\title{
Qualidade fisiológica das sementes de soja armazenadas em diferentes condições
}

\author{
Thaís A. de S. Smaniotto ${ }^{1}$, Osvaldo Resende ${ }^{2}$, Kaique A. F. Marçal ${ }^{3}$, \\ Daniel E. C. de Oliveira ${ }^{4} \&$ Gustavo A. Simon ${ }^{5}$
}

${ }^{1}$ IFG. Rio Verde, GO. E-mail: tatiadris@ig.com.br (Autor correspondente)

${ }^{2}$ IFG. Rio Verde, GO. E-mail: osvresende@yahoo.com.br

${ }^{3}$ IFG. Rio Verde, GO. E-mail: kaiqueafmarcal@yahoo.com.br

${ }^{4}$ UFMT. Sinop, MT. E-mail: oliveira.d.e.c@gmail.com

${ }^{5}$ UniRV. Rio Verde, GO. E-mail: guasimon@yahoo.com.br

\section{Palavras-chave:}

teor de água

temperatura

Glycine $\max (\mathrm{L}$.

\section{R E S U M O}

Propôs-se, neste trabalho, avaliar a qualidade fisiológica das sementes de soja ao longo do armazenamento durante 180 dias em diferentes teores de água e em duas condições de temperatura. Foram utilizadas sementes de soja, cultivar CD 242 RR com teores de água iniciais de 12, 13 e 14\% (b.u.). As sementes foram adquiridas com o teor de água de $11,0 \%$ (b.u.); em seguida, foram umedecidas em câmara BOD a $20^{\circ} \mathrm{C}$ e $85 \%$ de umidade relativa, homogeneizadas e acondicionadas em sacos plásticos de polipropileno; as embalagens foram mantidas em dois ambientes distintos. Com vista à avaliação das sementes ao longo do armazenamento foram realizadas as análises de teor de água, germinação, primeira contagem da germinação, índice de velocidade de germinação e condutividade elétrica. $\mathrm{O}$ experimento foi conduzido no delineamento inteiramente casualizado, segundo o esquema fatorial triplo $2 \times 4 \times 3$ (duas condições de armazenamento, quatro tempos de armazenamento e três teores de água), com três repetições. $\mathrm{O}$ teor de água inicial influencia na qualidade das sementes de soja durante o armazenamento. O ambiente climatizado $\left(20^{\circ} \mathrm{C}\right)$ proporciona melhores resultados em todas as características estudadas.

\section{Key words:}

moisture content temperature

Glycine $\max (\mathrm{L}$.

\section{Physiological quality of soybean seeds stored in different conditions}

\begin{abstract}
A B S T R A C T
The objective of this study was to evaluate the physiological quality of the soybean seed during storage for 180 days at different moisture contents and two temperatures. Seeds of soybean, cultivar CD 242RR with initial moisture contents of 12,13 and $14.0 \%$ (w.b.) were used. The seeds were acquired with a moisture content of $11.0 \%$ (w.b.), then were soaked in growth chamber at $20{ }^{\circ} \mathrm{C}$ and $85 \%$ relative humidity, homogenized and packed in polypropylene bags. The vials were kept in two different environments. For the evaluation of seeds during storage analysis of moisture content, germination, speed of germination and electrical conductivity were conducted. The experiment was conducted in a completely randomized design, according to the triple factorial $2 \times 4 \times 3$ (two storage conditions, four storage times and three levels of moisture) with three replications. The initial moisture content influenced the quality of soybean seeds during storage. The air-conditioned environment $\left(20^{\circ} \mathrm{C}\right)$ provided better results in all the studied traits.
\end{abstract}

\section{INTRODUÇÃO}

A soja, Glycine max (L.) Merrill é uma cultura de importância mundial sendo amplamente utilizada para a elaboração de rações animais, produção de óleo e outros subprodutos, além do seu consumo in natura que se vem expandindo nas últimas décadas (Araújo, 2009).

Segundo Ávila \& Albrecht (2010), a importância da soja também vem sendo enfatizada como alternativa na prevenção de doenças e na alimentação humana podendo ser transformada em diversos alimentos proteicos tais como, farinha, leite, proteína texturizada e creme e ainda para uso industrial na fabricação de derivados não tradicionais, como biodiesel, tintas e vernizes, entre outros.

Para atender à logística de produção e comercialização de alimentos a armazenagem dos produtos agrícolas é uma excelente alternativa. Desta forma, informações a respeito do comportamento das sementes diante das prováveis condições climáticas que ocorrem durante o armazenamento, podem auxiliar na tomada de decisão sobre o armazenamento do produto com base na relação custo-benefício, decorrente de possíveis perdas de qualidade na estocagem.

A qualidade da semente é fator de extrema importância para que se obtenha a produtividade esperada e o armazenamento 
é prática fundamental que pode ajudar na manutenção da qualidade fisiológica da semente sendo também um método por meio do qual se pode preservar a viabilidade das sementes e manter seu vigor até a futura semeadura (Azevedo et al., 2003). Para Cardoso et al. (2012), o processo de deterioração é inevitável mas pode ser retardado dependendo das condições de armazenamento e das características da semente.

Dentre os fatores que afetam a qualidade durante o armazenamento estão a temperatura e o teor de água da semente. Segundo Berbert et al. (2008), o teor de água é o fator de maior significância na prevenção da deterioração do grão durante o armazenamento. Mantendo-se baixo o teor de água e a temperatura do grão, o ataque de microrganismos e a respiração terão seus efeitos minimizados.

A temperatura e a umidade relativa são determinantes no processo de perda de viabilidade de sementes durante o armazenamento e alterações na qualidade do produto e, em contrapartida, dos subprodutos (Kong et al., 2008; Malaker et al., 2008).

Conforme Silva (2008) há um incremento na taxa respiratória proporcional ao aumento da temperatura, que fica na dependência do teor de água das sementes. Com o teor de água superior a $14 \%$ (b.u.) a respiração aumenta rapidamente na maioria dos cereais ocasionando sua deterioração.

De acordo com Demito \& Afonso (2009), a redução da temperatura é uma técnica economicamente viável para preservar a qualidade de sementes armazenadas.

A redução na qualidade é, em geral, traduzida pelo decréscimo na percentagem de germinação, aumento de plântulas anormais e redução no vigor das plântulas (Toledo et al., 2009).

Forti et al. (2010) observaram, através de testes de germinação e vigor, que o ambiente de armazenamento não controlado ocasionou maior redução do potencial fisiológico nas sementes de soja, em comparação com a câmara seca $(50 \%$ UR e $\left.20^{\circ} \mathrm{C}\right)$ e câmara fria $\left(90 \%\right.$ UR e $\left.10^{\circ} \mathrm{C}\right)$.

Diante do exposto objetivou-se, neste trabalho, avaliar a qualidade fisiológica das sementes da soja ao longo do armazenamento por 180 dias em diferentes condições de temperatura e teores de água.

\section{Material e Métodos}

O presente trabalho foi desenvolvido nos Laboratórios de Pós-Colheita de Produtos Vegetais e de Sementes do Instituto Federal de Educação, Ciência e Tecnologia Goiano (IF Goiano Câmpus Rio Verde), localizado no município de Rio Verde, GO.

Foram utilizadas sementes de soja (Glycine Max L.), cultivar CD 242 RR; as amostras das sementes de soja foram adquiridas de uma empresa privada, cultivadas no município de Formoso do Araguaia, TO, com teor de água de aproximadamente 11,0\% (b.u.).

Para obtenção dos teores de água de 12, 13 e 14\% (b.u.), as sementes foram previamente umedecidas em câmara BOD mantida na temperatura de $20{ }^{\circ} \mathrm{C}$ e umidade relativa de $85 \%$. Para acompanhar o ganho de massa as sementes foram pesadas em balança com resolução de $0,01 \mathrm{~g}$ até chegar ao teor de água desejado. Após se obter os teores de água as amostras foram homogeneizadas e acondicionadas em sacos plásticos de polipropileno, com capacidade para $1 \mathrm{~kg}$, por 180 dias. As embalagens foram mantidas em dois ambientes distintos: ambiente de laboratório com temperatura de $27 \pm 0,6^{\circ} \mathrm{C}$ e em ambiente climatizado com temperatura de $20 \pm 1,2^{\circ} \mathrm{C}$; durante o período de armazenamento a temperatura dos ambientes foi monitorada por meio de um registrador digital.

As embalagens plásticas de polipropileno foram utilizadas com o objetivo de manter os teores de água iniciais ao longo do armazenamento e foram submetidas a testes de permeabilidade utilizando-se o aparelho Permatran-W Model 1/50G. Minneapolis, MN-USA. O valor médio encontrado da permeabilidade foi de $7,345\left(\mathrm{~g} \mathrm{~m}^{-2} \mathrm{~d}^{-1}\right)$ a $38^{\circ} \mathrm{C}$.

Ao longo do armazenamento foram retiradas amostras de sementes a cada 60 dias $(0,60,120$ e 180 dias $)$ para avaliação da qualidade fisiológica das sementes de soja.

Visando à avaliação das sementes foram realizadas as análises de teor de água, germinação, primeira contagem da germinação, índice de velocidade de germinação (IVG) e condutividade elétrica.

A determinação do teor de água foi realizada por gravimetria utilizando-se a estufa a $105^{\circ} \mathrm{C}$, durante $24 \mathrm{~h}$, em duas repetições (Brasil, 2009).

O teste de germinação foi conduzido com 4 subamostras de 50 sementes de cada tratamento em rolos de papel toalha tipo "Germitest", em germinador tipo "Mangesdorf" regulado para manter a temperatura constante de $25 \pm 2{ }^{\circ} \mathrm{C}$; a quantidade de água adicionada foi equivalente a 2,5 vezes a massa do substrato seco visando ao umedecimento adequado e, consequentemente, a uniformização do teste. As interpretações foram efetuadas a partir do $1^{\circ}$ dia depois da semeadura, segundo os critérios estabelecidos nas Regras para Análise de Sementes (Brasil, 2009) computando-se o índice de velocidade de germinação e a porcentagem média de germinação.

A primeira contagem foi realizada juntamente com o teste de germinação sendo o registro da percentagem de plântulas normais verificado aos 5 dias após a instalação do teste.

O teste de condutividade elétrica foi realizado nas sementes de soja, segundo metodologia descrita por Vieira \& Krzyzanowski (1999) sendo contadas e pesadas quatro subamostras de 50 sementes, de cada tratamento. As amostras foram colocadas em copos de plástico com $75 \mathrm{~mL}$ de água deionizada e mantidas em uma câmara com temperatura controlada a $25^{\circ} \mathrm{C}$, durante $24 \mathrm{~h}$; depois deste período a leitura da condutividade elétrica foi realizada por meio de condutivímetro.

$\mathrm{O}$ experimento foi montado segundo o esquema em fatorial triplo $2 \times 4 \times 3$ (duas condições de armazenamento: 27 e $20^{\circ} \mathrm{C}$, quatro tempos de armazenamento: 0, 60, 120 e 180 dias e três teores de água: 12 , 13 e $14 \%$ b.u.) em delineamento inteiramente casualizado, com três repetições cujos dados foram analisados por meio de análise de variância e regressão e os selecionados com base na significância da equação, pelo teste F, na significância dos coeficientes de regressão utilizando-se o teste de " $\mathrm{t}$ " e se adotando o nível de 5\% de significância no 
coeficiente de determinação $\left(R^{2}\right)$ e no conhecimento da evolução do fenômeno biológico.

\section{Resultados e Discussão}

Na Figura 1 se encontram as temperaturas médias mensais dos ambientes de laboratório e climatizado, ao longo do tempo de armazenamento de sementes de soja.

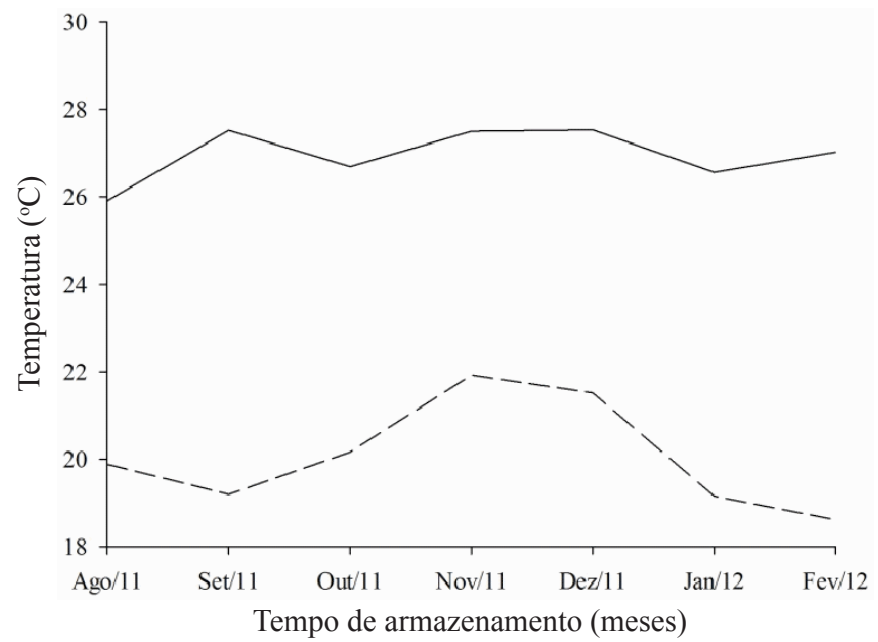

Figura 1. Temperaturas médias mensais dos ambientes de laboratório e climatizado ao longo do tempo de armazenamento das sementes de soja

A temperatura média no ambiente climatizado durante o armazenamento foi de $20^{\circ} \mathrm{C}$ sendo que a média máxima foi de $21,7^{\circ} \mathrm{C}$, registrada nos meses de novembro e dezembro e a média mínima foi de $18,9^{\circ} \mathrm{C}$, em janeiro e fevereiro.

No ambiente de laboratório a temperatura média foi de 27 ${ }^{\circ} \mathrm{C}$, os meses de agosto, outubro e janeiro apresentaram a média mínima de $26,4^{\circ} \mathrm{C}$ e a média máxima registrada nos meses de setembro, novembro, dezembro e fevereiro, foi de $27,4^{\circ} \mathrm{C}$.

Na Figura 2 se apresentam os valores experimentais e estimados do teor de água para as sementes de soja, ao longo

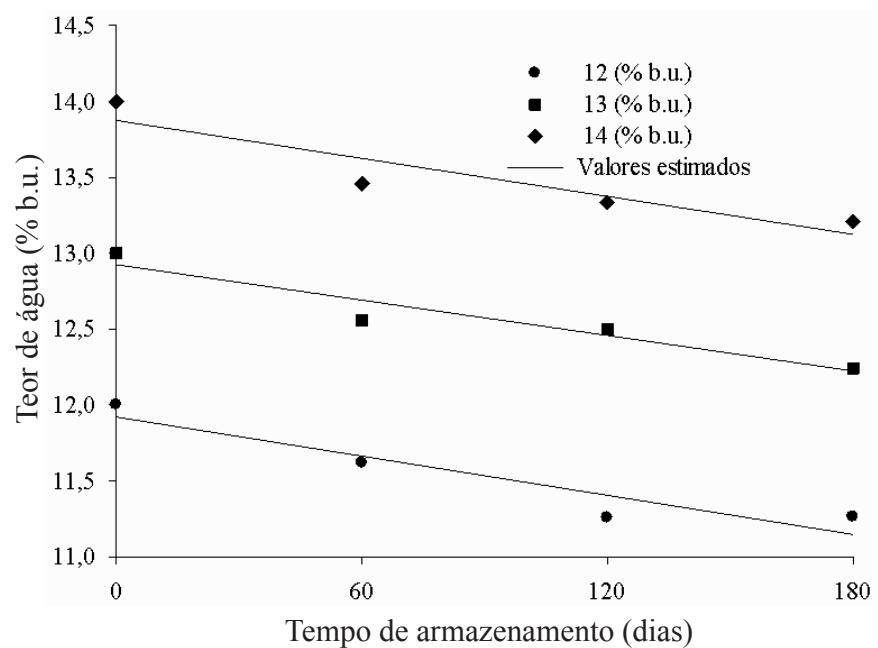

Figura 2. Valores experimentais e estimados do teor de água para as sementes de soja, ao longo do tempo de armazenamento do tempo de armazenamento. Nota-se, na Figura 2, que ocorreu decréscimo dos teores de água ao longo do armazenamento para todos os tratamentos (12, 13 e $14 \%$ b.u.) estudados sendo que no final dos 180 dias de armazenamento os teores de água foram de 11,16; 12,24 e 13,21\% (b.u.).

Esta redução do teor de água pode ser relacionada com a permeabilidade da embalagem em que as sementes foram armazenadas de vez que o tipo de embalagem utilizada permite troca de vapor d'água com o ambiente, o que ocorre em razão das sementes e os grãos serem higroscópicos, sujeitos aos processos de sorção, ou seja, seu teor de água está sempre em equilíbrio com a umidade relativa e a temperatura do ar.

Demito \& Afonso (2009) verificaram, analisando os resultados de diversos trabalhos, redução do teor de água na soja resfriada em virtude de uma provável secagem na camada superficial dos grãos; já Alencar et al. (2008) observaram aumento no teor de água para os grãos de soja armazenados com teor de água de $14,8 \%$ (b.u.) a $30{ }^{\circ} \mathrm{C}$ e $83 \%$ de UR e 12,8 e $14,8 \%$ (b.u.) na temperatura de $40{ }^{\circ} \mathrm{C}$ e UR e de 80 e $86 \%$, respectivamente devido à atividade respiratória dos grãos e da microflora associada.

Na Tabela 1 estão apresentadas as equações lineares ajustadas para os valores de teor de água em função do tempo de armazenamento; nota-se que as equações lineares podem ser usadas para descrever a perda de água das sementes de soja ao longo do armazenamento, nas embalagens plásticas utilizadas.

Tabela 1. Equações lineares ajustadas para os valores de teor de água (TA) em função do tempo de armazenamento (Ep)

\begin{tabular}{ccccc}
\hline $\begin{array}{c}\text { Teor de } \\
\text { água (\% b.u.) }\end{array}$ & $\begin{array}{c}\text { Equação } \\
\text { linear }\end{array}$ & $\mathbf{R}^{\mathbf{2}}$ & $\mathbf{F}$ & $\begin{array}{c}\mathbf{P} \\
\text { level }\end{array}$ \\
12 & $\mathrm{TA}=11,9199^{\star}-0,0043 \mathrm{Ep}$ & 0,8841 & 15,25 & 0,059 \\
13 & $\mathrm{TA}=12,9246^{*}-0,0039 \mathrm{Ep}$ & 0,9146 & 21,40 & 0,044 \\
14 & $\mathrm{TA}=13,8751^{\star}-0,0042 \mathrm{Ep}$ & 0,8575 & 12,04 & 0,074 \\
\hline
\end{tabular}

TA - Teor de água (\% b.u.); Ep - Tempo de armazenamento (dias); ${ }^{*}$ Significativo a 0,01

$\mathrm{O}$ armazenamento de sementes de soja nos teores de água de 12,13 e $14 \%$ (b.u.) na temperatura de $20^{\circ} \mathrm{C}$, não afetou a primeira contagem de germinação sendo que os valores médios no final do armazenamento foram $99,8 \%$ para o teor de água inicial de $12 \%$ (b.u.) e 99,3\% para os teores de água iniciais de 13 e $14 \%$ (b.u.).

$\mathrm{Na}$ Figura 3 se apresentam os resultados da primeira contagem em função do teor de água e do tempo de armazenamento para a temperatura de $27^{\circ} \mathrm{C}$.

Verifica-se, na Figura 3, que houve decréscimo durante o armazenamento na temperatura de $27^{\circ} \mathrm{C}$ para todos os teores de água iniciais, em que este foi mais acentuado para o teor de água de $14 \%$ (b.u.) chegando, ao final, com $76,1 \%$. Esta maior perda de vigor comparada às demais se deve à combinação da temperatura $\left(27^{\circ} \mathrm{C}\right)$ e ao maior teor de água (14\% b.u.). Referidos dados corroboram com os de Bahry et al. (2008) que verificaram, em experimento com milheto, baixo vigor na condição de armazenamento por 18 meses em ambiente não controlado e Barbosa et al. (2010) observaram perda de vigor nas sementes de soja durante os seis meses de 




Figura 3. Valores experimentais e estimados da primeira contagem das sementes de soja em função do teor de água inicial e do tempo de armazenamento para a temperatura de $27^{\circ} \mathrm{C}$

armazenamento com temperatura de $23^{\circ} \mathrm{C}$ e umidade relativa do ar de $60 \%$.

Outros pesquisadores constataram redução nos valores de primeira contagem da germinação ao longo do armazenamento utilizando sementes de crambe durante nove meses, em diferentes embalagens (Cardoso et al., 2012).

$\mathrm{Na}$ Tabela 2 estão as equações ajustadas para os valores de primeira contagem de germinação em função do tempo de armazenamento para a temperatura de $27^{\circ} \mathrm{C}$. Nota-se que a equação linear no teor de água de $12,0 \%$ (b.u.), pode ser usada para descrever o comportamento da primeira contagem ao longo do tempo. As equações quadráticas nos teores de água de 13 e $14 \%$ (b.u.), mesmo não sendo significativas a $5 \%$, descrevem o comportamento ao longo do tempo de armazenamento.

Nas Figuras 4 e 5 estão apresentados os valores da germinação e do IVG das sementes de soja em função do teor de água e do tempo de armazenamento para as temperaturas de 20 e $27^{\circ} \mathrm{C}$, respectivamente.

Verifica-se, na Figura 4A, que ocorreu, para o teor de água inicial de $12 \%$ (b.u.) um decréscimo até os 120 dias seguido de um aumento aos 180 dias de armazenamento com total de $100 \%$ de germinação.

Os teores de água inicias de 13 e $14 \%$ (b.u.) sofreram decréscimo no decorrer do armazenamento chegando aos 180 dias com 99,3\% de sementes germinadas permanecendo ainda com uma excelente germinação ao final do armazenamento.

Tabela 2. Equações ajustadas para os valores de primeira contagem (PC) em função do tempo de armazenamento (Ep) para a temperatura de $27^{\circ} \mathrm{C}$

\begin{tabular}{ccrrr}
\hline $\begin{array}{c}\text { Teor de } \\
\text { água } \\
\text { (\% b.u) }\end{array}$ & Equação linear & $\mathbf{R}^{2}$ & $\mathbf{F}$ & $\begin{array}{c}\mathbf{P} \\
\text { level }\end{array}$ \\
12 & $\mathrm{PC}=100,0333^{\star *}-0,0050^{*} \mathrm{Ep}$ & 0,9529 & 40,50 & 0,023 \\
13 & $\mathrm{PC}=99,7750^{\mathrm{NS}}+0,0365^{\mathrm{NS}} \mathrm{Ep}-0,0004^{\mathrm{NS}} \mathrm{Ep}^{2}$ & 0,9896 & 15,97 & 0,174 \\
14 & $\mathrm{PC}=100,3533^{* *}+0,0248^{\mathrm{NS}} \mathrm{Ep}-0,0009^{\mathrm{NS}} \mathrm{Ep}^{2}$ & 0,9935 & 75,91 & 0,081 \\
\hline
\end{tabular}

Ep: tempo de armazenamento (dias); ${ }^{* *}$ Significativa a 0,$01 ;{ }^{*}$ Significativa a 0,05 e Ns Não significativa pelo teste de $\mathrm{F}$

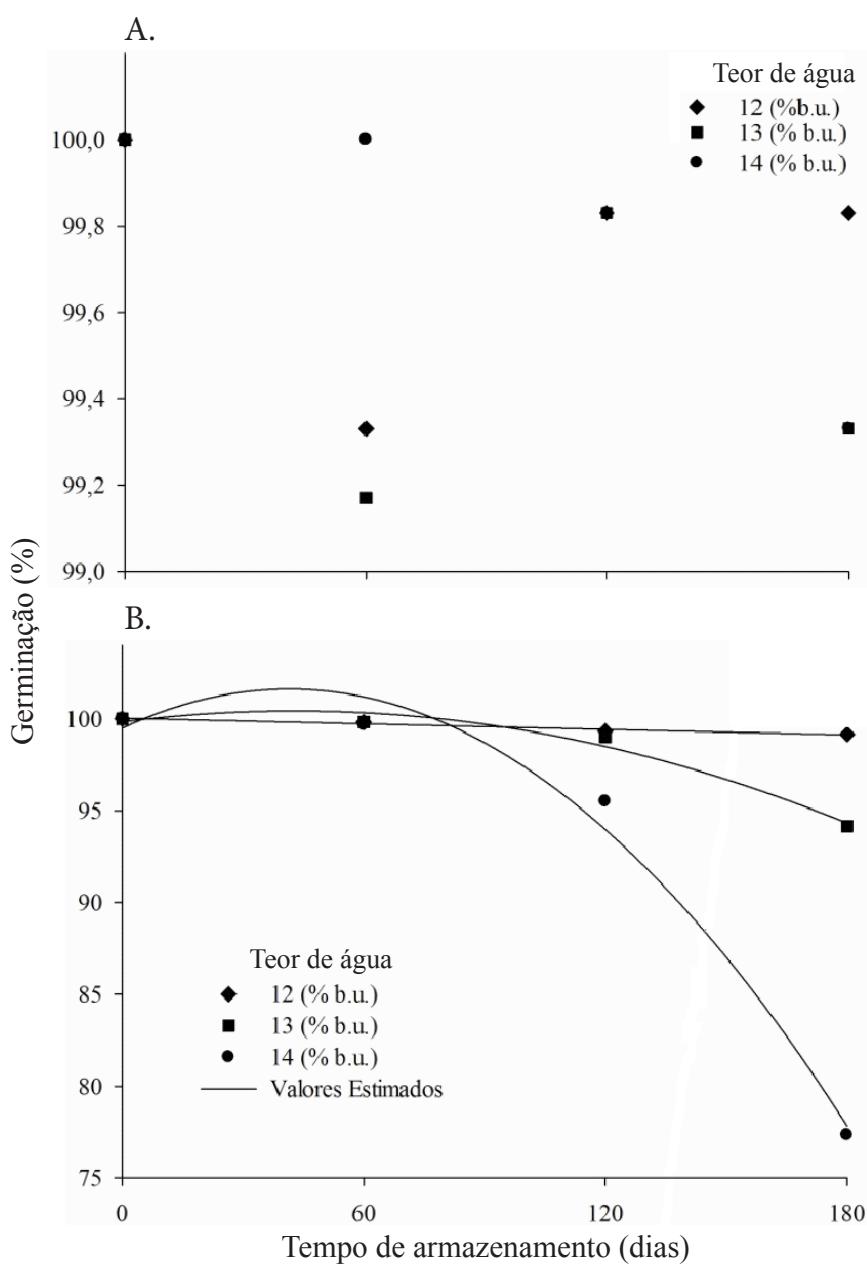

Figura 4. Valores experimentais da germinação das sementes de soja, em função do teor de água inicial e do tempo de armazenamento para as temperaturas de 20 (A) e $27^{\circ} \mathrm{C}(\mathrm{B})$

Porto (2004) observou que, quando resfriadas, as sementes mantiveram a qualidade fisiológica por mais de seis meses.

De acordo com Cunha et al. (2009), a deterioração pode intensificar-se com o prolongamento do período de armazenamento, mesmo em ambiente refrigerado.

Estevão \& Possamai (2002) ressaltam que as sementes de soja perdem sua viabilidade após 120 dias de armazenamento em condições tropicais simuladas (câmara a $25^{\circ} \mathrm{C}$ e $85 \%$ de UR), mas o resfriamento artificial manteve a qualidade fisiológica de sementes de milho e soja durante o armazenamento (Carvalho \& Silva, 1994).

Demito \& Afonso (2009), verificaram que as sementes resfriadas artificialmente $\left(12\right.$ a $\left.15^{\circ} \mathrm{C}\right)$, mantiveram o poder germinativo durante o armazenamento (140 dias), conforme o padrão comercial, segundo eles em razão das melhores condições de armazenagem justificadas pelos menores valores de temperatura durante o período de conservação.

$\mathrm{Na}$ Figura 4B nota-se, para o teor de água inicial de 12\% (b.u.) uma pequena redução da germinação a partir dos 60 dias permanecendo praticamente constante ao final do armazenamento com valor de 99,6\%. Para o teor de água inicial de $13 \%$ (b.u.) houve uma redução no decorrer do armazenamento 
A.

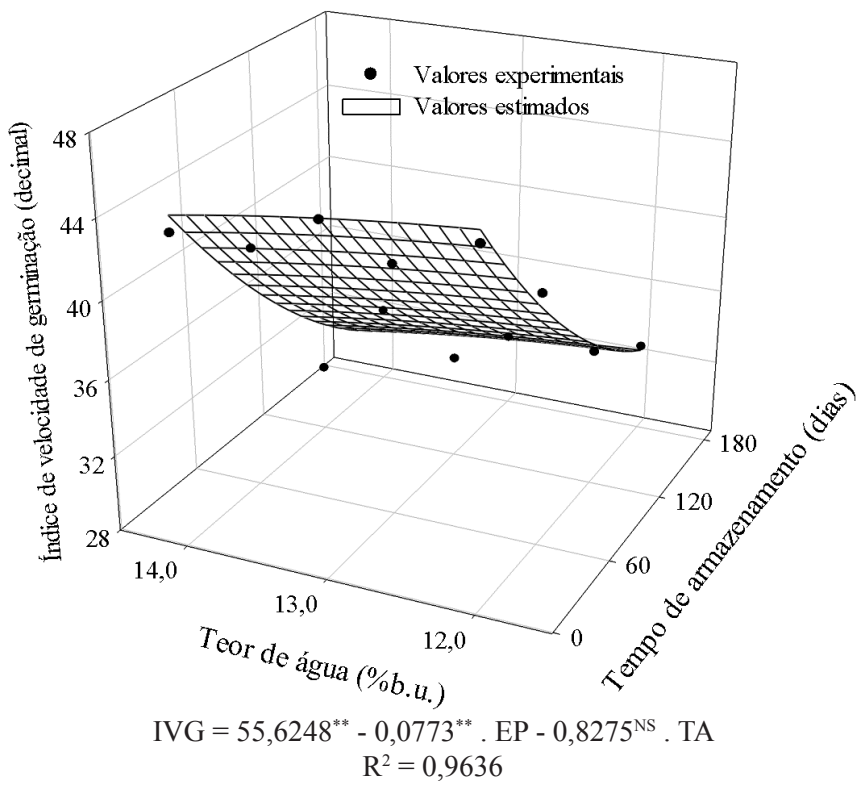

B.

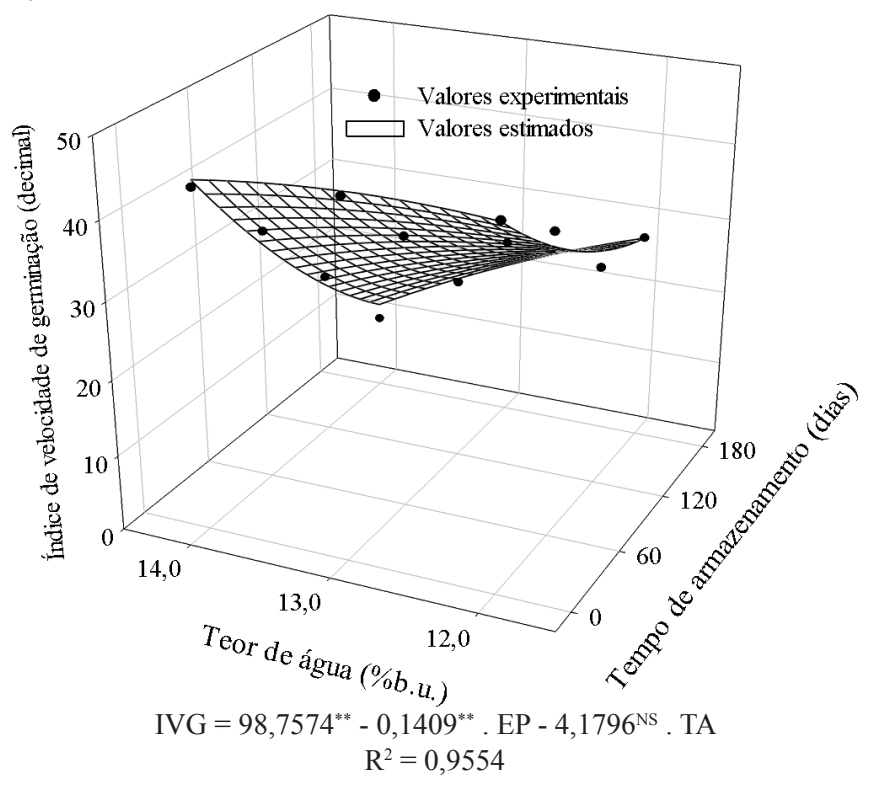

${ }^{*}$ Significativo a 0,01; Ns Não significativa pelo teste de $t$

Figura 5. Valores experimentais e estimados do índice de velocidade de germinação (IVG) das sementes de soja, em função do teor de água (TA) e do tempo de armazenamento (Ep) para as temperaturas de 20 (A) e $27^{\circ} \mathrm{C}(\mathrm{B})$

chegando aos 180 dias com 94,16\% de germinação; já para o teor de água inicial de $14 \%$ (b.u.) verificou-se uma redução maior da germinação no decorrer do armazenamento com o valor de $77,3 \%$ no final dos 180 dias de armazenamento.

As sementes tendem a perder o vigor e a germinação durante o armazenamento devido a peroxidação dos lipídeos, juntamente com um alto teor de água e temperatura, ser passível de ter provocado esta maior queda na germinação comprovando que o teor de água das sementes influencia na qualidade fisiológica durante o armazenamento.

A qualidade da soja também é influenciada pelas condições de armazenagem enquanto combinações de temperatura e teores de água mais elevados intensificam a deterioração do produto (Alencar et al., 2008). Em geral, as sementes de soja, quando armazenadas em temperatura ambiente e em armazéns convencionais, degradam suas qualidades fisiológicas dando margem a perdas consideráveis no setor sementeiro (Demito \& Afonso, 2009).

A deterioração qualitativa de soja armazenada com teores iniciais de água entre 9,8 e 13,8\% (b.u.), em condições tropicais $\left(30{ }^{\circ} \mathrm{C}\right.$ e $82 \%$ UR), foi simulada por Locher \& Bucheli (1998) que verificararam diminuição acentuada do percentual de germinação entre 5 e 9 meses de armazenamento comportamento este mais acentuado nas sementes com maior teor inicial de água.

Diversos autores estudaram a germinação nas sementes de soja. Almeida et al. (2010) observaram queda linear na germinação das sementes de soja durante o armazenamento de 180 dias, em condições ambientais. Afonso Júnior et al. (2000) verificaram redução significativa na viabilidade das sementes de soja a partir dos 10 dias de armazenamento para teores de água mais elevados (15 e 20\% b.u.). Mencionados pesquisadores constataram que o potencial de germinação das sementes diminuiu com o aumento do teor de água das sementes, da temperatura e do período de armazenagem.

Na Tabela 3 estão apresentadas as equações ajustadas para os valores de germinação em função do tempo de armazenamento para a temperatura de $27^{\circ} \mathrm{C}$. Nota-se que a equação linear para o teor de água de $12 \%$ (b.u.), pode ser usada para descrever o comportamento da germinação ao longo do tempo. As equações quadráticas nos teores de água de 13 e $14 \%$ (b.u.), mesmo não sendo significativas a 0,05 , descrevem adequadamente $o$ comportamento, ao longo do tempo de armazenamento.

Apresentam-se, na Figura 5 (A e B), as superfícies de resposta para o IVG em função do teor de água e do tempo de armazenamento para as temperaturas de 20 e $27^{\circ} \mathrm{C}$, respectivamente.

Quanto ao fator período de armazenagem, observa-se que o IVG das sementes de soja tende a decrescer significativamente ao longo do tempo para todos os teores de água estudados. De início, esses valores passaram de 45,8; 45,7 e 43,9 para 32,7;31,8 e 32,0 no final do armazenamento, nos teores de água iniciais de 12, 13 e 14\% (b.u.), respectivamente (Figura 5A).

$\mathrm{Na}$ Figura 5B percebe-se que houve um decréscimo no IVG no decorrer dos 180 dias de armazenamento para os teores iniciais de água estudados. Braccini et al. (1997) também obtiveram resultados semelhantes em sementes de soja

Tabela 3. Equações ajustadas para os valores de germinação (G) em função do tempo de armazenamento (Ep) para a temperatura de $27^{\circ} \mathrm{C}$

\begin{tabular}{|c|c|c|c|c|}
\hline $\begin{array}{c}\text { Teor de } \\
\text { água } \\
\text { (\% b.u) }\end{array}$ & Equação & $\mathbf{R}^{2}$ & $\mathbf{F}$ & $\begin{array}{c}P \\
\text { level }\end{array}$ \\
\hline 12 & $\mathrm{G}=100,0333^{* *}-0,0050^{*} \mathrm{Ep}$ & 0,9544 & 41,87 & 0,023 \\
\hline 13 & $\mathrm{G}=99,83^{*}+0,0278^{\mathrm{NS}} \mathrm{Ep}-0,0003^{\mathrm{NS}} \mathrm{Ep}^{2}$ & 0,9754 & 19,86 & 0,156 \\
\hline 14 & $\mathrm{G}=99,49^{*}+0,1027^{\mathrm{NS}} \mathrm{Ep}-0,0012^{\mathrm{NS}} \mathrm{Ep}^{2}$ & 0,9850 & 32,94 & 0,122 \\
\hline
\end{tabular}
significativa pelo teste de $\mathrm{F}$ 
armazenadas por 0, 3 e 6 meses em condição ambiente. Para Silva \& Vieira (2006), entre os testes de vigor mais conhecidos inclui-se o IVG, que é de fácil execução, uma vez que a coleta de dados é efetuada no próprio teste de germinação. O teste de velocidade de germinação considera que lotes cujas sementes germinam mais rápido, são mais vigorosos havendo relação direta entre velocidade de germinação e vigor das sementes.

Verifica-se, também, que os teores de água influenciaram no IVG sendo que o teor de água inicial de $12 \%$ (b.u.) obteve resultados superiores aos de $13 \%$ (b.u.) e este, por sua vez, foi superior ao de $14 \%$ (b.u.).

Este decréscimo no IVG é devido à deterioração das sementes ao longo do armazenamento agravado pela temperatura e pelo teor de água em que as sementes foram armazenadas. Segundo Salinas et al. (2001), a qualidade das sementes diminui com o transcorrer do tempo e a taxa de deterioração depende das condições ambientais durante o armazenamento e do tempo em que permanecem armazenadas.

Na Figura 6 (A e B) se encontram as superfícies de resposta da condutividade elétrica para a soja em função do teor de água e do tempo de armazenamento para as temperaturas de 20 e 27 ${ }^{\circ} \mathrm{C}$, respectivamente.

Para os teores iniciais de água estudados e para as duas temperaturas analisadas verifica-se a crescente liberação de eletrólitos das sementes para a água de embebição durante o período de armazenamento sendo este um indicativo de perda de vigor e qualidade fisiológica no armazenamento. Este fato também foi observado por pesquisadores trabalhando com soja armazenada em diversas condições (Silva et al., 2010; Zuchi et al., 2013). O aumento da condutividade elétrica no decorrer do armazenamento pode estar relacionado ao reumedecimento das sementes que pode ter promovido uma danificação maior no sistema de membranas.

Verifica-se acréscimo maior na condutividade elétrica na solução de sementes com teor de água de 14\% (b.u.). Vários autores utilizaram a condutividade elétrica como parâmetro qualitativo de grãos. Em resultados encontrados por Yaja et al. (2005), que armazenaram sementes de soja com quatro teores de água, 6, 8, 10 e 12\% (b.u.), nas temperaturas de 15, 20, 25 e $35^{\circ} \mathrm{C}$, também obtiveram incremento da condutividade elétrica na solução de sementes após 120 dias. Krishnan et al. (2004) também verificaram valores médios maiores de condutividade elétrica da solução que continha os grãos à medida que se utilizavam temperaturas mais elevadas ao longo do período de armazenamento estudando as características termodinâmicas da soja durante o armazenamento em condições de envelhecimento acelerado.

Observa-se também que o teor de água inicial de $12 \%$ (b.u.) apresentou menor valor de condutividade elétrica permitindo melhor conservação da qualidade inicial das sementes.

Alencar et al. (2008), observaram resultados semelhantes armazenando grãos de soja em diferentes teores de água $(11,2$; $12,8$ e $14,8 \%$ b.u. $)$ e temperatura $\left(20,30\right.$ e $\left.40{ }^{\circ} \mathrm{C}\right)$. Esses autores verificaram, também, que os melhores resultados foram obtidos nos menores teores de água e temperatura.

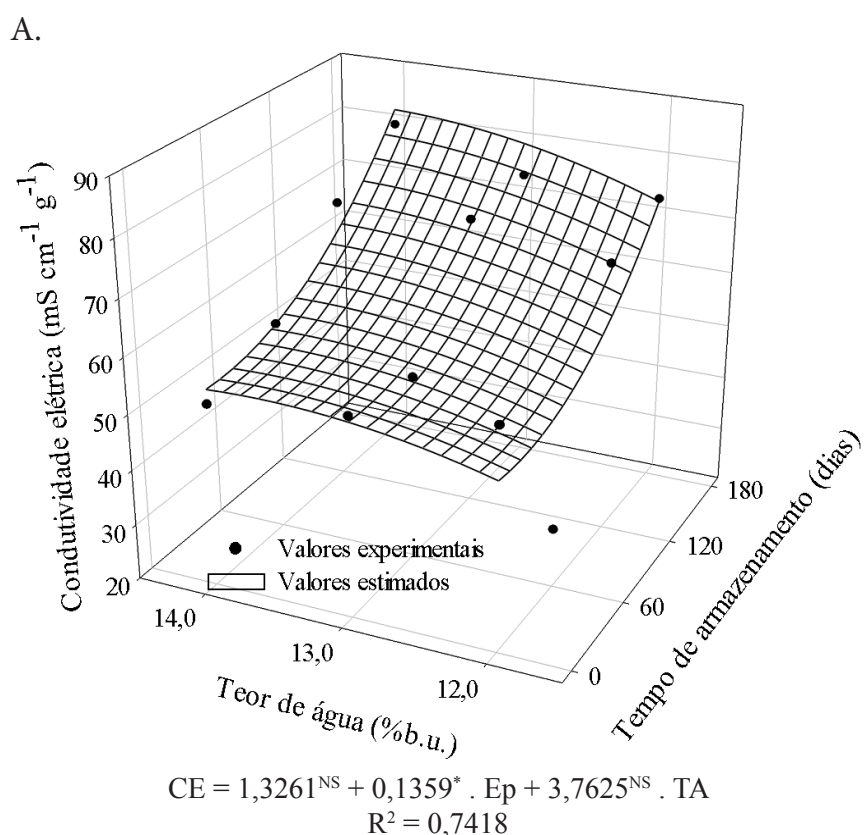

B.

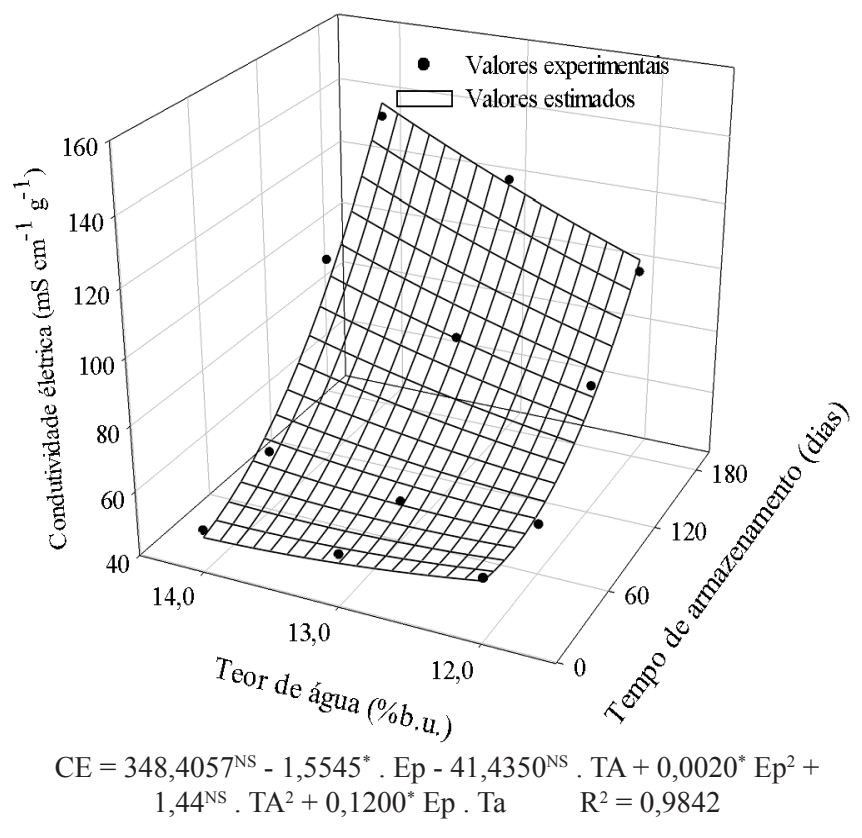

* Significativo a 0,05 ; Ns Não significativa pelo teste de $t$

Figura 6. Valores experimentais e estimados da condutividade elétrica (CE) da solução de sementes de soja, em função do teor de água (TA) e do tempo de armazenamento (Ep) para a temperatura de 20 (A) e $27{ }^{\circ} \mathrm{C}(\mathrm{B})$

\section{Conclusões}

1. O teor de água inicial influencia na qualidade das sementes de soja durante o armazenamento sendo que as sementes armazenadas com teor de água inicial mais elevado, $14 \%$ (b.u.) apresentam maior perda de qualidade no decorrer do armazenamento.

2. O ambiente climatizado $\left(20^{\circ} \mathrm{C}\right)$ proporciona melhor conservação da qualidade fisiológica das sementes de soja, em todas as condições analisadas. 
3. O menor teor de água inicial, 12\% (b.u.), mantém as sementes com maior qualidade sendo recomendado para conservação do vigor das sementes de soja.

\section{Agradecimentos}

Ao CNPq, à CAPES, à FAPEG e ao IF Goiano, pelo apoio financeiro indispensável à execução do trabalho.

\section{Literatura Citada}

Afonso Júnior, P. C.; Corrêa, P. C.; Faroni, L. R. D. Efeito das condições e período de armazenagem sobre a viabilidade de sementes de soja. Revista Brasileira de Oleaginosas e Fibrosas, v.4, p.1-7, 2000.

Alencar, E. R. de; Faroni, L. R. D.; Lacerda Filho, A. F.de; Ferreira, L. G.; Meneghitti, M. R. Qualidade dos grãos de soja em função das condições de armazenamento. Engenharia na Agricultura, v.16, p.155-166, 2008.

Almeida, F. de A. C.; Jerônimo, E. de S.; Alves, N. M. C.; Gomes, J. P.; Silva, A. S. Estudo de técnicas para o armazenamento de cinco oleaginosas em condições ambientais e criogênicas. Revista Brasileira de Produtos Agroindustriais, v.12, p.189202, 2010.

Araújo, M. M. Caracterização e seleção de linhagens de soja resistentes ou tolerantes à ferrugem asiática.Piracicaba: ESALQ, 2009. 77p. Dissertação Mestrado

Ávila, M. R.; Albrecht, L. P. Isoflavonas e a qualidade das sementes de soja. Informativo Abrates, v.20, p.15-29, 2010.

Azevedo, M. R. de Q. A.; Gouveia, J. P. G. de; Trovão, D. M. M.; Queiroga, V. de P. Influência das embalagens e condições de armazenamento no vigor de sementes de gergelim. Revista Brasileira de Engenharia Agrícola e Ambiental, v.7, p.519524, 2003.

Bahry, C. A.; Muniz, M. F. B.; Franzin, S. M.; Casaroli, D.; Garcia, D. C.; Antonello, L. M. Influência do armazenamento na qualidade fisiológica e sanitária de sementes de milheto. Pesquisa Agropecuária Gaúcha, v.14, p.119-124, 2008.

Barbosa, C. Z. dos R.; Smiderle, O. J.; Alves, J. M. A.; Vilarinho, A. A.; Sediyama, T. Qualidade de sementes de soja BRS Tracajá, colhidas em Roraima em função do tamanho no armazenamento. Revista Ciência Agronômica, v.41, p.7380, 2010.

Berbert, P. A.; Silva, J. S.; Rufato, S.; Afonso, A. D. L. Indicadores da qualidade dos grãos. In: Silva, J. S. (Ed) Secagem e armazenagem de produtos agrícolas. Viçosa: Aprenda Fácil, 2008. p.63-107.

Brasil. Ministério da Agricultura e Reforma Agrária. Secretaria Nacional de defesa Agropecuária. Regras para análise de sementes. Brasília, 2009. 395p.

Braccini, A. L.; Reis, M. S.; Sediyama, C. S.; Rocha, V. S.; Sediyama, T. Influência do processo de hidratação: desidratação na qualidade fisiológica de sementes de soja durante o armazenamento. Revista Brasileira de Sementes, v.19, p.80-87, 1997.
Cardoso, R. B.; Binotti, F. F. da S.; Cardoso, E. D. Potencial fisiológico de sementes de crambe em função de embalagens e armazenamento. Pesquisa Agropecuária Tropical, v.42, p.272-278, 2012.

Carvalho, M. L. M. de; Silva, W. R. da. Refrigeração e qualidade de sementes de milho armazenadas em pilhas com diferentes embalagens. Revista Agropecuária Brasileira, v.9, p.13191332, 1994.

Cunha, J. P. A. R. da; Oliveira, P. de; Santos, C. M. dos; Mion, R. L. Qualidade das sementes de soja após a colheita com dois tipos de colhedora e dois períodos de armazenamento. Ciência Rural, v.39, p.1420-1425, 2009.

Demito, A.; Afonso, A. D. L. Qualidade das sementes de soja resfriadas artificialmente. Engenharia na Agricultura, v.17, p.7-14, 2009.

Estevão, C. P.; Possamai, E. Qualidade fisiológica e sanitária de sementes de soja tratadas e armazenadas em diferentes ambientes. Scientia Agraria, v.3, p.113-132, 2002.

Forti, V. A.; Cicero, S. M.; Pinto, T. L. F. Avaliação da evolução de danos por 'umidade' e redução do vigor em sementes de soja, cultivar TMG 113-RR, durante o armazenamento, utilizando imagens de raio $X$ e testes de potencial fisiológico. Revista Brasileira de Sementes, v.32, p.123133, 2010.

Kong, F.; Chang, S. K. C.; Liu, Z.; Wilson, L. A. Changes of soybean quality during storage as related to soymilk and tofu making. Journal of Food Science, v.73, p.134-144, 2008.

Krishnan, P.; Nagarajan, S.; Moharir, A.V. Thermodynamic characterization of seed deterioration during storage under accelerated ageing conditions. Biosystems Engineering, v.89, p.425-433, 2004.

Locher, R.; Bucheli, P. Comparison of soluble sugar degradation in soybean seed under simulated tropical storage conditions. Crop Science, v.38, p.1229-1235, 1998.

Malaker, P. K.; Mian, I. H.; Bhuiyan, K. A.; Akanda, A. M.; Reza, M. M. A. Effect of storage containers and time on seed quality of wheat. Bangladesh Journal of Agricultural Research, v.33, p.469-477, 2008.

Porto, A.G. Resfriamento de sementes de soja em silo com sistema de distribuição radial do ar. Pelotas: UFPEL, 2004. 47p. Tese Doutorado

Salinas, A. R.; Yoldjian, A. M.; Craviotto, R. M.; Bisaro, V. Pruebas de vigor y calidad fisiológica de semillas de soja. Pesquisa Agropecuária Brasileira, v.36, p.371379, 2001.

Silva, F. S. da; Porto, A. G.; Pascuali, L. C.; Silva, F. T. C. da. Viabilidade do armazenamento de sementes em diferentes embalagens para pequenas propriedades rurais. Revista de Ciências Agroambientais, v.8, p.45-56, 2010.

Silva, J. B. da; Viera, R. D. Avaliação do potencial fisiológica de sementes de beterraba. Revista Brasileira de Sementes. Revista Brasileira de Sementes, v.28, p.128-134, 2006.

Silva, J. S. Secagem e armazenagem de produtos agrícolas, Viçosa: Aprenda Fácil, 2008. 560p. 
Toledo, M. Z.; Fonseca, N. R.; César, M. L.; Soratto, R. P.; Cavariani, C.; Crusciol, C. A. C. Qualidade fisiológica e armazenamento de sementes de feijão em função da aplicação tardia de nitrogênio em cobertura. Pesquisa Agropecuária Tropical, v.39, p.124-133, 2009.

Vieira, R. D.; Krzyzanowski, F. C. Teste de condutividade elétrica. In: Krzyzanowski, F. C.; Vieira, R. D.; França Neto, J. B. (ed.). Vigor de sementes: Conceitos e testes. Londrina: ABRATES, 1999. Cap.4, p.1-26.
Yaja, J.; Pawelzik, E.; Vearasilp, S. Prediction of soybean seed quality in relation to seed moisture content and storage temperature. In: Conference on International Agricultural Research for Development. 8, 2005, Stuttgart-Hohenheim. Proceedings... Stuttgart-Hohenheim: Chaingmai University, 2005. 4p.

Zuchi, J.; França Neto, J. B.; Sediyama, C. S.; Lacerda Filho, A. F.; Reis, M. S.Physiological quality of dynamically cooled and stored soybean seeds. Journal of Seed Science. Journal of Seed Science, v.35, p.353-360, 2013. 